\title{
Improving environmental education among students of philology by the business game method
}

\author{
Sergey Yekimov",*, Yaroslava Shven ${ }^{2}$ Hennadii Karimov ${ }^{3}$, Anna Tolstova ${ }^{4}$ and \\ Nataliia Chupryna ${ }^{5}$ \\ ${ }^{1}$ Publishing House "Education and Science" s.r.o., Olstynska 607/1, Praha 8 , 18100 ,Czech \\ Republic \\ ${ }^{2}$ Institution of Higher Education "University of Educational Management" National Academy of \\ Educational Sciences of Ukraine, 52 A, Sichovykh Striltsiv Street, Kyiv, Ukraine \\ ${ }^{3}$ Dniprovsk State Technical University , Dnipropetrovsk region; Kamianske, Dniprobudivska Street, \\ 2, Ukraine \\ ${ }^{4}$ Ukrainian State University of Railway Transport, Feijerbakha Square, 7, Kharkiv, Kharkiv Oblast, \\ Ukraine \\ ${ }^{5}$ SHEI Ukrainian State University of Chemical Technology, 8 Gagarin Avenue, Dnipro, \\ Dnipropetrovsk Oblast,Ukraine
}

\begin{abstract}
The training of modern specialists in the field of philology, and in particular the formation of their communicative competence, is a very complex and time-consuming process, which depends on a variety of objective and subjective factors. In this study, we used the business game method to increase the level of environmental education and communicative competence of students of philology. Environmental education provides an opportunity to create the necessary conditions for the sustainable development of the economy and society. In most industrialized countries, there are trends towards saving the natural resources consumed, and waste recycling is also used to reuse the useful resources contained in them. In our opinion, sustainable socio-economic development should provide for the preservation of the fauna and flora, the fertility of the land, as well as the cleanliness of the air space for future generations. We believe that this requires the availability of high-quality environmental education among specialists in various areas of human activity. The results of the business game showed an increase in students ' communicative competence, as well as an increase in environmental education and the desire to protect the environment.
\end{abstract}

\section{Introduction}

The training of modern specialists for the implementation of their professional activities, as well as the process of forming their communicative competence, is a very time-consuming and complex process, depending on various subjective and objective

\footnotetext{
* Corresponding author (Автор-корреспондент): 3701313@mail.ru
} 
aspects. The objective aspects, in our opinion, include the shortcomings of the educational and methodological support of the educational process. The subjective aspects include the insufficient training of the teaching staff in the methodological and methodological plan in the direction of educating modern specialists in communicative competence, as well as the low level of motivation of students to participate in the educational process.

Modern requirements for communication competence according to [1] should include the ability to take part in international seminars, meetings and meetings, skills of professional and business correspondence, as well as communication by telephone using a foreign language.

In the opinion of [2] the communicative competence should include the skills to discuss issues related to professional activity.

According to [3] communicative competence is a set of theoretical knowledge and practical skills in the field of professional communication, which characterize the professional training of a specialist .

According to [4] communication competence is the most important quality of modern specialists, due to the fact that professional communication is the basis for success in most areas of professional activity.

According to [5] preparation for professional communication is an integral component of a modern specialist. This type of competence is formed through the study of foreign languages .

In the opinion of [6] communicative competence contributes to the formation of specialists ' skills of the ability to conduct discussions on professional topics and defend their point of view in them, as well as to better understand interpersonal relationships and avoid conflict situations in communication.

According to [7] communicative competence contributes to the formation of a professional as a person.

In the modern world, environmental problems occupy an important place among the problems faced by modern society. The main causes of environmental disasters have arisen as a result of the use of intensive technological processes in nature management, while the potential for sustainability of natural complexes is at a low level. The growth of mineral extraction, the use of mineral fertilizers and pesticides cause huge damage to the environment. Pollution of the human environment has led to an increase in cancer and reduced immunity in humans.

In the opinion of [8] the solution of many environmental problems can be promoted not only by the work of ecologists, but also by the system of universal environmental education.

According to [9] environmental education should have an interdisciplinary, universal character and be included in all forms of general and professional education.

In the opinion of [10] society needs a continuous educational process that would contribute to the formation of a system of values necessary for respect for the environment.

According to [11] environmental protection activities should be reoriented from the control of environmental pollution to the prevention of this pollution.

In the opinion of [12] economic activities should comply with the principles of respect for the environment, and the general public should have the right of free access to various environmental information.

Modern ecology is a complex of knowledge functioning on the basis of technical , natural, humanitarian and social sciences.

Knowledge in the field of ecology, in our opinion, is necessary for specialists working in various fields of professional activity. They should, in our opinion, be able to take environmentally appropriate actions in various problematic situations.

The formation of modern students of various specialties of the need to carry out 
independent educational activities in the field of ecology, according to the opinion of [13] It is one of the most important problems facing modern education.

In the opinion of [14] the system of environmental education should be based on the principles of environmental ethics. Environmental ethics is based on a system of moral attitudes and requirements, the observance of which should contribute to the development and preservation of human existence.

Nature and man are components of the system of the world. In this regard, in the opinion of [15] regardless of the type of professional activity, each person should be familiar with the basic concepts and principles of environmental ethics, which will allow achieving harmony in the evolutionary development of the socio-ecosystem.

Environmental ethics is based on three basic principles [16] (Figure 1) :

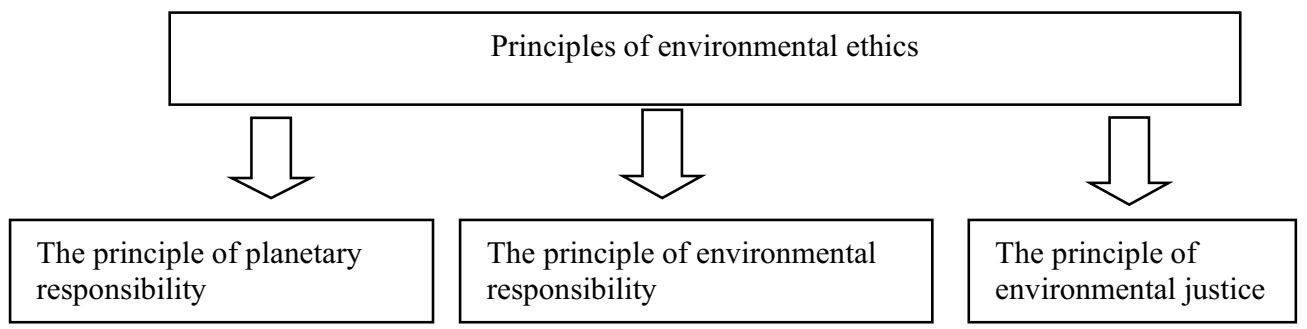

Fig. 1. Basic principles of environmental ethics

The principle of environmental responsibility provides for the feasibility of limiting human activities for the possibility of survival in the future. The principle of planetary responsibility provides for the responsibility of all mankind for its future. The principle of environmental justice provides for fair treatment of their future descendants, who may suffer because of the interests of people living in the present.

According to [17] humanity should not enter into various contradictions with the laws of the development of nature and society, since this can cause negative processes that will occur in the biosphere.

According to [18] compliance with the basic principles of environmental ethics should be made a conscious need and moral necessity of people, they should penetrate into the most diverse spheres of human activity, such as politics, education and economics.

We adhere to the point of view that environmental ethics will allow us to achieve harmony between nature and man based on the principles of morality and high spirituality of humanity.

The result of environmental education, according to [19], can be the formation of an ecological culture that would be characterized by knowledge about the social and natural environment, a careful attitude to nature, as well as personal active participation in environmental activities.

\section{Methods}

During the implementation of this research work, the authors used an analytical method by which the problems studied in it were considered in their development and unity.

Taking into account the goals and objectives of this scientific research, a functional and structural method of conducting scientific research was used.

In the end, this allowed us to consider some issues related to the use of the business 
game for environmental education..

\section{Results}

In the framework of this study, we used the pedagogical technology of the business game to improve the level of environmental education among students of the Faculty of Philology of the Dnipro University.

At the beginning of the study, we conducted a survey of students, which found out :

1) What environmental issues do they care about?

2) Who needs to address environmental issues?

3) Whether it is necessary for students studying philology to additionally study the basics of ecology.

According to the results of the survey of students, the following results were obtained:

1) $76 \%$ of respondents indicated that they are concerned about environmental pollution from transport and industrial enterprises , $21 \%$ of respondents indicated their concern about the problem of environmental pollution from household waste.

2) $85 \%$ of respondents reported that only specialized state organizations should be engaged in solving environmental problems , $13 \%$ of respondents reported that it is the duty of every citizen to solve environmental problems.

3) $74 \%$ of respondents reported that students studying philology do not need to study the basics of ecology in addition , 19\% of respondents would like to study the basics of ecology as an optional course.

The theme of our proposed business game was "Green Tourism". At the beginning of the business game, the students were divided into two teams. One team played the role of a travel agency, whose employees had to offer green tourism services in a foreign language, the second team performed the functions of foreign tourists who were interested in green tourism services in the vicinity of the city of Dnipro. At the beginning of the business game, the tourist team informed the travel agent team what local attractions they wanted to visit. The team of travel agents had to prepare information about the attractions that the team of tourists would like to visit and offer an electronic presentation of these attractions. When performing an electronic presentation, the team members of the travel agents team studied the information about these attractions posted in open sources, went out to take photos related to these attractions.

As a result of the work carried out, the team of travel agents came to the conclusion that many objects that can be used for green tourism are in a poor ecological situation and the associated environmental problems require urgent solutions.

The results of the study of the team of travel agents were presented in a presentation to which experts from local environmental organizations were invited to demonstrate.

After the end of the business game, we re-conducted the student survey on the same questions that were used at the beginning of the study

According to the results of the survey of students, the following results were obtained:

1) $55 \%$ of respondents reported that only specialized state organizations should be engaged in solving environmental problems , $43 \%$ of respondents reported that it is the duty of every citizen to solve environmental problems.

2) $58 \%$ of respondents reported that students studying philology do not need to study the basics of ecology in addition , 39\% of respondents would like to study the basics of ecology as an optional course. 


\section{Discussion}

The use of business games in foreign language classes in order to improve the level of environmental education has yielded the following results:

1) Students achieved a higher level of professional communication, as their communication related to tourism and environmental activities.

2) Due to the fact that many graduates of philological specialties, in the future ,associate their professional activities with the tourism industry, students have acquired some necessary skills.

3) Participation in the role-playing game allowed students to gain skills of teamwork, the success of which depended on the well-coordinated work of all team members.

4) Students got independent work with various sources of information

5) As a result of participation in the business game, the students' work showed elements of creative activity and the associated sense of satisfaction with the results achieved.

6) Students understood the importance of environmental protection measures for the preservation of the environment, as well as the need for the participation of the entire society in this process.

\section{Conclusions}

Effective environmental education will create the necessary conditions for the sustainable development of society and the economy. In the industrialized economies of the world, there is a tendency to save the consumed natural resources, as well as the use of technologies that reduce the negative impact on the environment. Recycling of waste for the reuse of the valuable resources contained in it has become widespread.

Sustainable development, in our opinion, should mean preserving for future generations the flora and fauna, the purity of the air and the fertility of the land.

We adhere to the point of view that this is possible with high-quality environmental education from specialists in all areas of human activity.

Environmental education should promote the development, formation and consolidation, along with the necessary knowledge, of certain stereotypes in people's behavior that encourage them to act in accordance with environmental standards and norms.

Environmental education, in our opinion, should become the most important, integral part of the modern education system.

Environmental education should contribute to the formation of the young generation of ecological culture, ecological thinking and environmental awareness, as well as promote the promotion of a healthy lifestyle.

Environmental education can create a sense of responsibility for the preservation of the natural environment among today's young people.

\section{References}

1. T. Taş \& Ö. Khan, On the Models of Communicative Competence. (2020)

2. R. Rubin, Ph. Palmgreen, \& H. Sypher, In book: Communication Research Measures 10.4324/9781003064343-17. (Routledge, New-York, 2020).

3. L.K. Turabaeva, Eurasian Union Scientists, 3, 37-40 (2020).

4. J. O. Greene, The Nature of Communication Skill and Communication Competence. (2021). 
5. A. Allen, Communicative Competence. (2019).

6. Y. Kirilova \& V. Vasileva, Intercultural aspects of communicative competence (2020).

7. H. Aslonova, The American J. of Social Science and Education Innovations, 02, 490493 (2020)

8. T. Olatunde-Aiyedun, Fundamentals of Environmental Education. (2021).

9. W. Scott \& P. Vare, Environmentally educated teachers (2020).

10. P. Pihkala, Sustainability, 12, 10149 (2020).

11. N. Ochilova, Theoretical \& Applied Science, 81, 769-771 (2020).

12. B. Hayward, Environmental education for a chaotic climate. (2020).

13. S. Burch, Environmental education. (2018).

14. B. Bhat, S. Bandh \& S. Shafi, Environmental Education and Environmental Impact Assessment (2020).

15. N. Khadka, Banko Janakari, 10, 60. (2017).

16. A. Akinsemolu, Environmental Ethics. (2020).

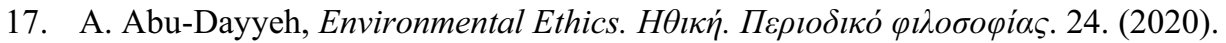

18. W. Lee, Environmental Ethics. (2019).

19. Z. Abduazimova, Environmental ethics and globalization. Critical survey. (2020). 